\title{
Porphyria cutanea tarda and Sjogren's syndrome*
}

\author{
Fang $\mathrm{Su}^{1}$ \\ DanYang Song ${ }^{1}$
}

\author{
XiaoJie $\operatorname{Sun}^{1}$ \\ TieNan $\mathrm{Li}^{1}$
}

ZanFeng Wang ${ }^{2}$

DOI: http://dx.doi.org/10.1590/abd1806-4841.20142969

Abstract: Porphyria cutanea tarda is prevalent in connective tissue disease, common in systemic lupus erythematosus. However, the co-existence of primary sjogren's syndrome and porphyria cutanea tarda is rare and poses diagnostic and therapeutic challenges. We report a case of porphyria cutanea tarda associated with primary sjogren's syndrome.

Keywords: Porphyria cutanea tarda; Sjogren's syndrome; Skin and connective tissue diseases

A 61-year-old female patient presented with increased skin pigmentation for a month in the summer of 2009, with increased skin fragility and blisters on her forearms and hands, as well as significant scarring. Three weeks later, these skin lesions gradually subsided. Throughout the following three years, skin lesions worsened in spring and summer, and abated in autumn and winter. In the summer of 2012, erythema and blisters appeared on the double forearm and extensor muscles of the leg. She also reported general pain and malaise, skin darkening, and yellowish urine. Subsequently, she was admitted to hospital. Past disease history: she denied smoking and drinking; hepatitis and tuberculosis were also denied.

Physical examination: The blood pressure level was $120 / 70 \mathrm{mmHg}$, and body temperature $36.8^{\circ} \mathrm{C}$. No jaundice and was generally in good condition. Facial hypertrichosis was present as the darkened skin and foreseeable pigmentation. Several patches of round or oval erythema were visible on the back of both hands and extensor muscles of both legs, accompanied by erosions, shallow ulcers, even necrosis and scabs. The shallow scars scattered on the hand back, with Dean posi- tive signs. No milia were seen. Severe dental caries were observed. Upon examination, results for the joints, lungs, abdomen, and chest were normal (Figure 1).

Laboratory tests: Blood routine test: white blood cell $3.48-3.52 \times 10^{9} / \mathrm{L}$, neutrophil 1.58 $1.95 \times 10^{9} / \mathrm{L}$, red blood cell $3.15-3.15 \times 10^{12} / \mathrm{L}$, platelet $65-70 \times 10^{\circ} / \mathrm{L}$; liver function test: ALP 188 IU/L(RV: 34 $150 \mathrm{IU} / \mathrm{L})$, GGT $86 \mathrm{IU} / \mathrm{L}(\mathrm{RV}: 0-5 \mathrm{IU} / \mathrm{L})$, ESR 120 $\mathrm{mm} / \mathrm{h}$; renal function, stool routine, urine routine were normal; HbsAg (Hepatitis B) negative , HIV(Human Immunodeficiency Virus), HVA (hepatitis A) and HVC (hepatitis C) serology were negative, tuberculosis antibody was negative, ferritin 496.7 $\mathrm{ng} / \mathrm{mL}(\mathrm{RV}:<200 \mathrm{ng} / \mathrm{mL}$ ), coproporphyrins and uroporphyrin were positive and the free protoporphyrins level was $3483 \mathrm{~g} / \mathrm{dl}$ (RV up to $60 \mathrm{mg} / \mathrm{dl}$ ). Abdominal ultrasonography revealed fatty liver; electrocardiogram and chest $\mathrm{X}$-ray were normal. Skin histopathological examination: squamous epithelial tissue, local skin ulceration, ulceration, dermal vessel wall fibrinoid degeneration, inflammatory cell infiltration on vascular wall, acid-fast staining and PAS staining were negative (Figure 2).

\footnotetext{
Received on 14.07.2013.

Approved by the Advisory Board and accepted for publication on 16.08.2013

Work performed at the Seventh People`s Hospital of Shenyang and First Affiliated Hospital of China Medical University - Shenyang, China. Conflict of interest: None.

Financial Support: None.

Seventh People's Hospital of Shenyang - Shenyang, China.

First Affiliated Hospital of China Medical University - Shenyang, China.

(C2014 by Anais Brasileiros de Dermatologia
} 


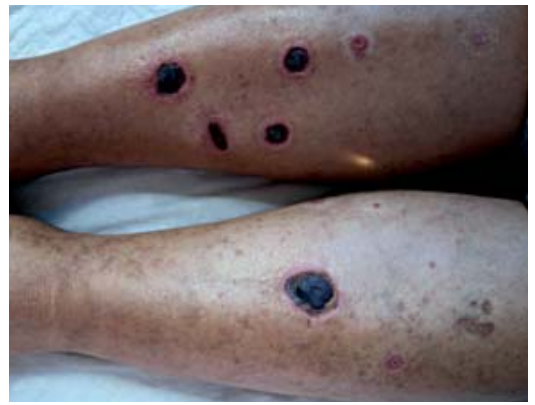

Figure 1:

Several patches of round or oval erythema on the extensor muscles of both legs, accompanied by erosions, shallow ulcers, necrosis and scab

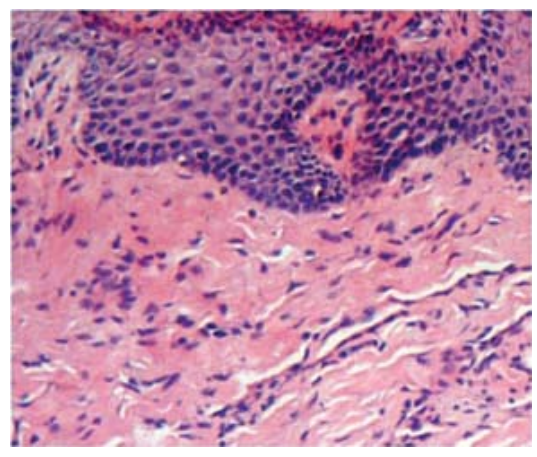

Figure 2:

Histological section of skin biopsy sample showing dermal vessel wall fibrinoid dege$\mathrm{n}$ e r a tio $\mathrm{n}$, inflammatory cell infiltration on vascular wall

The preliminary diagnosis was Porphyria cutanea tard. In the treatment process, we found a decrease in white blood cells, red blood cells, and platelet in the patient, who had also presented teeth exfoliate, a dry mouth and dry eyes during the previous three years, often needing the application of artificial tears. No oral ulcers, hair loss or joint pain was reported. From the patient's clinical manifestations, we considered the existence of Sjogren's syndrome and duly performed bone marrow puncture and labial gland biopsy. Meanwhile, the patient was given oral hydroxychloroquine $200 \mathrm{mg}$ / twice a week for the treatment of PCT.

Bone marrow puncture results showed bone marrow hyperplasia, with no thromocytogenic megakaryocyte. ANA +(1:3200), ds-DNA -, U1RNP - , SM -, ENA -, SA +, SSB ++++, ANCA ( - ), (PR3-ANCA -, MPO-ANCA - ), IgG: 22.45g/L(RV:7-16.6g/L), IgA,
IgM were normal, C3: $0.75 \mathrm{~g} / \mathrm{L}(\mathrm{RV}: 0.8-1.2 \mathrm{~g} / \mathrm{L})$, C4:0.079g/L(RV:0.1-0.4g/L). Histopathological examination of labial gland showed normal labial gland contour, partial labial gland atrophy, expanded ducts and lymphocytes infiltrated in the lobule. All symptoms supported Sjogren's syndrome. After the patient was treated with oral methylprednisolone tablets $24 \mathrm{mg} /$ day for two weeks, skin lesions appeared with scabs, with no new lesions; blood routine examinations were normal, and the patient was still under follow-up.

Sjogren's syndrome is a systemic autoimmune disease, mainly involving exocrine glands and divided into primary and secondary types, and the latter is associated with certain diffuse connective tissues such as rheumatoid arthritis, systemic lupus erythematosus, and systemic sclerosis. The patient had no history of other connective tissue disease and was thus diagnosed with primary Sjogren's syndrome.

Porphyria cutanea tarda is prevalent in connective tissue disease, common in systemic lupus erythematosus, followed by dermatomyositis. In 1952, Wolfram $S$ et al. first reported the existence of acute intermittent porphyria in a case with systemic lupus erythematosus. ${ }^{1}$ Information has gradually been collected on systemic lupus erythematosus that complicate a variety of porphyria. However, the correlation between systemic lupus erythematosus and porphyria remains unclear. ${ }^{2-5}$ Sjogren's syndrome in patients with porphyria cutanea tarda is rare; only Ramasamy $\mathrm{R}$ reported a case in $1982 .{ }^{6}$ In our study, the patient suffered from a dry mouth, dry eyes, rampant tooth, occasional skin rash and facial hair for three years, which all supported primary Sjogren's syndrome. Therefore, we suspect that this case is porphyria cutanea tarda accompanied by Sjogren's syndrome. Further studies are needed to focus on the pathophysiology between the two, or they just occasionally occur in one patient. Scleroderma patients were also found to present porphyria cutanea tarda symptoms. Hence, more diligence is needed to ascertain whether porphyria cutanea tarda is associated with autoimmune diseases. ${ }^{7} \square$ 


\section{REFERENCES}

1. Wolfram S. Colic caused by porphyrin; symptomatology of the acute erythematodes. Hautarzt. 1952;3:298-300.

2. Vickers $\mathrm{CFH}$, Sneddon IB. Subacute systemic lupus erythematosus: porphyria. $\mathrm{Br} \mathrm{J}$ Dermatol. 1962;74:155-6.

3. Nicholson GD, Prussia PR, Garriques S. Coexistence of porphyria cutanea tarda and systemic lupus erythematosus. West Indian Med J. 1988;37:232-5.

4. Gibson GE, McEvoy MT. Coexistence of lupus erythematosus and porphyria cutanea tarda in fifteen patients. J Am Acad Dermatol. 1998;38:569-73.

5. Fritsch S, Wojcik AS, Schade L, Machota Junior MM, Brenner FM, Paiva Edos S Increased photosensitivity? Case report of porphyria cutanea tarda associated with systemic lupus erythematosus. Rev Bras Reumatol. 2012;52:968-70.

6. Ramasamy R, Kubik MM. Porphyria cutanea tarda in association with Sjögren's syndrome. Practitioner. 1982;226:1297-8.

7. Thomas CL, Badminton MN, Rendall JR, Anstey AV. Sclerodermatous changes of face, neck and scalp associated with familial porphyria cutanea tarda. Clin Exp Dermatol. 2008:33:422-4.

\author{
MAILING ADDRESS: \\ Xiaojie Sun \\ Dongwei Road 13,heping \\ District \\ shenyang, China \\ E-mail: sufangfang2007@163.com
}

How to cite this article: Su F, Sun XJ, Wang ZF, Song DY, Li TN. Porphyria cutanea tarda and Sjogren's syndrome. An Bras Dermatol. 2014;89(4):689-91. 